\title{
Research of Individual Credit System Based On Risk Prevention of Credit Card
}

\author{
Zeng Ming \\ School of Economic and Management, Shanghai Second Polytechnic University, Pudong New Area, \\ Shanghai, China \\ zengming@sspu.edu.cn
}

Keywords: Credit card, Individual credit system, Commercial bank

\begin{abstract}
The source and course of credit card risk are elaborated in this paper, and the defects of individual credit system used in our country's nowadays banking are analyzed as well. The individual credit system for credit card in America is learned in this paper, and the related improving methods for individual credit system in our country's nowadays banking are proposed, including: improving nowadays credit system; enforcing the quality verification for credit data; establishing a complete individual credit evaluation system; enforcing the sharing of individual credit information among banks, in order to prevent the risk of credit card better.
\end{abstract}

\section{The source and course of credit card risk}

\subsection{The definition of credit card risk}

Credit card is one kind of common credit tools. It is issued by credit card offers (usually can be commercial banks) according to credit card holders' credit rating and financial status. Using the credit card, holders need not pay cash when they are consuming, and pay the bill on the date bank send the statement for the bill.

In the broad sense, credit card risk means the possibility of loss of the credit card offer, the credit card holder and the merchant which is caused by disadvantageous factors. In the narrow sense, credit card risk is specifically defined as the possibility of loss of the credit card offer because of a verity of reasons during the using process of credit cards. Credit card risk can be damaging, it is necessary to be prevented carefully.

\subsection{The source of credit card risk}

\subsubsection{Risks from credit card holder}

The first one is overdrawing with evil intention. The second one is that the credit card holder lies that he doesn't receive the goods. The third one is that after reporting loss, use a huge amount of credit cards which have been reported loss. The fourth one is that lending money at usury using the overdraw amount.

\subsubsection{Risks from merchant}

The first one is the fraud by lawless employees. In reality, employees have the chance to contact with the information of customers' credit card, even can take the credit card away out of customers' sight. Lawless employees will consume using customers' credit cards and detain the invoice created by the consumption, which will lead to the loss of customers. The second one is the fraud by lawless merchants. Lawless merchants induce the customer to login their own website by using the similar domain name and e-mails as famous stores. Customers have difficulty in judging whether it is true or not, and will submit payment information easily. The shopkeeper will forge the invoice and ask for money from bank using forged invoice.

\subsubsection{Risks from third parties}

The first one is theft. The thief will do large quantity of transaction quickly, until the credit card is reported loss by the legal credit card holder and frozen by bank. The second one is copy. In the places like hotel and restaurant, authorization usually happens out of credit card holders' sight, which makes it possible for lawless employees to acquire magnetic stripe information by portable card reader. The third one is ATM fraud. The fraud happened on the ATM usually can be the password being stolen or forged, even can be robbing. The fourth one is forging. The criminal will 
acquire customer's credit card data at first, like stealing or install receive devices on keyboard and attacking online banks by hackers, and then use forge credit cards to commit fraud. The fifth one is falsifying others identity, including the theft of consumer's identity and merchant's identity. The sixth one is false reporting. Criminals apply for credit cards with forge identity and creditworthy materials or lie that they have lost their cards, and then commit fraud consume or deposit cash, which will lead to the loss of the bank.

\subsection{Factors affected credit card risk}

\subsubsection{The asymmetry of credit cards holder's credit rating and bank's information}

Credit card holders' credit rating is uncertain. Firstly, credit card holder's consumption behavior is uncertain, a card holder who behaves well can overdraw with evil intention for various reasons. Secondly, credit card holder's financial status is uncertain, which can be affected by factors like card holder's job, income and asset loss. And the card issued bank's risk will increase for these reasons.

\subsubsection{Some rules of credit cards offers chances for criminals}

One of the credit card issue rules says" There is no need to ask for any permission if the credit card is used under the credit limit when consuming and deposit cash.” This rule is a double-edged sword, which not only gives convenience to the credit holder, but also gives them the key to the bank vault. Whether the credit card holder will use this key or not totally depends on holder's willing, while the card issued bank's preventive measures tend to lag.

\subsubsection{Accounting checking not in time will increase the loss}

Because of the defect of credit card accounting, and some of the bank outlets and employees from merchants delay on consumption and deposit of credit card accounting checking, credit

Issued bank will not realize the loss until the deposit and consumption under the credit limit pour in.

\section{The defect of bank individual credit system in China}

Nowadays, credit cards in China are mainly issued by each commercial banks and affiliated credit card companies (shorted as card issued bank). Although each of them has their own individual credit system, there are many defects.

\subsection{Credit system is imperfect}

The current individual credit system cannot update in time, there are many situations that the omitting and miss of data and information happens and the information query system is not convenient enough. The first one is that the time needed to update system data information is too long, and some of the update period of time is far behind the prescribed time, which will influence borrower's re-financing. The second one is that when facing some important data query in system, the reflection of the content is not comprehensive and accurate enough. The situations that data is being omitting and missed are common. The third one is that credit report is not clear enough, which cannot be understood easily. And this results in that judging the credit situation of the party from report can be hard. The fourth one is that the process speed of data query is slow, there are also some occasions that system cannot be login, which will influence ordinary work.

\subsection{There is difficulty in collecting individual credit data}

Some institutions and organizations which possess credit data cannot coordinate with each other fluently, and the collection of individual data is more difficult. In China, individual credit data is mainly mastered by government departments like People's Bank of China, public security, courts, Administration for Industry and Commerce, Tax Agency, labor security and personnel department. And some non-government institutions including commercial banks, public services, postal services, telecommunication services, mobile communication services and insurance institutions also own individual credit information. But among these departments and institutions, there is a lack of sharing and they are not open to each other, which is different from the developed countries, those who will share their information openly. 


\subsection{Lack of complete data for estimating individual credit}

In China, the credit data that citizens can provide mainly includes citizen ID card, residential certificate, personnel files and personal asset certificate (eg. certificate of deposit account, material possessions etc.). Each commercial bank has its own credit estimation system, and the core index and index weighted are not unified, which leads to the huge difference in estimation results and having difficulty in comparing with each other. Estimating index system overemphasize data can be clearly seen like individual occupation, income and family asset, but ignore the individual development potential. Credit estimation overemphasizes on mortgage and assurance and neglects the borrower's own ability to pay back the money. For the sake of that personal asset declaration system and personal basic account system have not been established in China, there are no complete records of individual incomes and expenditures, creditor's rights and liabilities, which mean that there is a lack of basic data of individual credit estimation.

\subsection{Difficult cooperation among card issued banks}

Currently, each card issued banks are using different credit card devices, software and Internet patterns, which cannot be compatible. At the same time, credit cards from different banks are not able to be used under the different network, so the information communication cannot go well, which is the reason for there is no effective way to share resources and control the risk.

\section{Reflection to perfect bank individual credit system in China}

\subsection{Brief introduction to individual credit system of credit card in America}

During the 20 century, individual credit has developed very fast in America. Retail credit and installment credit appeared in succession. Credit card was born in 1950s in America, which is issued by bank or other financial companies to individuals. Using the credit card, card holders can use their individual credit in a broader geographical area and get cash from ATM. In America, the measures and laws are taken to prevent credit card's credit are as follow.

3.1.1 Provide individual credit report in detail

In America, credit report is provided by credit bureau to client himself and legitimate body and individual according to laws. Credit report mainly includes four parts. (1)Individual identity information: Besides common personal information, there are also Social Security Number, occupation, position and employer's information. (2) Public record information: Individual bankrupt information, court litigation and judgment record, taxation impounding record and asset judgment record are included. (3) Individual credit information: The start date of each credit account, line of credit, loan amount and balance, repay amount of each month and the situation of loan repayment for last 7 months are included. (4) Query record: The name of inquirer and the purpose of query are included.

\subsubsection{Having perfect individual credit estimation system}

Credit-rating is based on credit report, application, materials of social public record and the credit history of the borrower. The data that credit-rating will use are divided into five parts, by order of importance are presented as follow: (1) individual bankrupt record, impounding and mortgage goods, arrears of debt (2) debt outstanding (3) the period of credit history (4) times of query for new loan application in recent 1 year (5) the type of credit or the type of credit card you have

\subsubsection{Having gigantic individual credit system}

In America, the system of individual credit system is very huge, covering all of the country. Three credit bureaus, Equifax, Experian, Trans Union, have been a triangular balance of power, and cooperate with over 1000 local credit bureau all over America, collecting credit information of nearly 200 million adults.

\subsection{What we can learn from individual credit system in America}

The history of credit card business in America is long, so lots of experience both on law's environment and practical operation are accumulated. Credit card business in China is still 
developing, and we can learn something from American individual credit system to prevent credit card risk.

\subsubsection{Ought to perfect individual credit file}

Individual financial and credit file is the basis of individual credit business. In foreign countries, before the financial institution issue credit card to individual, they will inquire the applicant's credit situation from certain institutions, which tend to be the professional individual credit file enrollment institution. Like credit bureau and credit report bureau in America, whose information is complete and comprehensive, they can provide applicant's credit category and balance, using situation in past time, payback history and other information.

3.2.2 Ought to establish individual credit estimation system

Banks in America formed a perfect individual credit system on the basis of over hundred years' history. Banks can inquire individual credit file from individual credit database at any time and determine whether give the applicant's credit limit or not and the credit limit rapidly. On the basis of establishment of individual financial and credit file system, these institutions give every client's scientific and accurate credit rating evaluation, helping financial institution make right decision on credit businesses. By establishing different credit rating model for different customers and using scientific and rational estimating methods, Individual financial and credit estimation system provide the basis of credit risk management in banks and other financial institution.

3.2.3 Ought to establish individual credit risk early warning system

Early warning system will be the first key step. If the credit risk is prevented properly, the difficulty of the following credit risk management will be decreased to a great extent. Once problems on client's account and other signs that will affect bank's financial safety are showed, banks must strengthen connection with the client and take related measures like lower the client's credit rating to prevent risks.

\subsection{Suggestions to perfect individual credit system}

\subsubsection{Improve the quality of individual credit data}

Commercial banks should reinforce the inspecting of individual credit data, and ensure the quality of data. Insist on the data quality inspecting method which gives data checking on both side priority and regards designated monitoring as supplement, perfecting the method of data quality inspecting. Establish and perfect the checking mechanism of designated inspecting of individual credit data, improve sample coverage rate, arrange checking frequency rationally. Only in this way, can the credit card holders' credit rating be estimated more accurately during the credit card business operation process.

3.3.2 Improve individual credit system

Commercial banks should regard credit card itself as carrier, perfecting individual credit enrollment system based on data of credit card being used. Nowadays, credit card can store basic personal information (eg. name, gender, occupation). Besides basic personal information, credit card database also should have personal credit line, consumption information, evil-intention overdraw and other information. If use these information as basis, extending individual credit related information further, individual credit record can be done better and improve commercial bank's individual credit system.

\subsubsection{Strengthen the supervision of individual credit system}

China Banking Regulatory Commission should strengthen the supervision and management of individual credit system, establish and improve the supervision mechanism of related credit system and supervise commercial bank's creditability. Blame should be assigned if commercial banks do not send the client's payback information in time and reflect client's true situation. At the same time, the credit systems of commercial banks and China Banking Regulatory Commission should be linked in time, which can make individual credit system play an important role in credit card risk prevention. 


\section{Conclusion}

At present, the new session of Central Government has made the decision: We should make great efforts to establish the credit system, strengthen the construction of integrity of government affairs, the integrity of business, the integrity of society and judicial credibility, and time should be seized to establish the credit system which can covering the whole society. So, I firmly believe that under this environment, individual credit system will be perfect day by day.

\section{Acknowledgement}

This research was financially supported by Finance cultivate discipline special funding of Shanghai Second Polytechnic University (Grant No. XXKPY1306).

\section{References}

[1] Miller,MJ . Credit Reporting Systems and the International Economy[M]. The MIT Press, 2003

[2] Jin Zhang, Research on Laws of Credit Card Risk Prevention [J], Legal System and Society, 2009(1): 151-152

[3] Liangfang Zheng, Research on Construction of China's Credit Information System [J], Credit Reference, 2010(1): 40-42

[4] Jinyan Zhang, On the Perfect of the Law of China's Credit Card Risk Management [M], Press of Fudan University, 2011

[5] Qun Liu, Brief Discussion on Promotion the Quality of Credit System Data [J], West China Finance, 2010(9): 55-56

[6] Mei Zhang, Meng Luo, View on Risk Prevention of Credit Card According to Credit Card Fraud [J], China Credit Card, 2009(1): 58-59 